Martin Kralik - Michaela Hola - Stanislav Jurecka*

\title{
OPTICAL PROPERTIES OF POROUS SILICON SOLAR CELLS FOR USE IN TRANSPORT
}

Porous silicon ( $\mathrm{pSi}$ ) samples were prepared by electrochemical etching of p-type silicon ( $p$-type Si) substrate. Three pSi samples with different parameters of electrochemical etching (electrical potential, etching time, etching current) were prepared and analyzed. We studied the influence of electrochemical etching parameters on spectral reflectance of pSi structure. A modification of interference pattern was observed due to changes of microstructure. We determined the thickness of pSi layers from spectral reflectance. Solar cells with a porous structure achieve high efficiency and long life. These solar cells are predestined for use in transport.

Keywords: electrochemical etching, black silicon, porous silicon, spectral reflectance, thin film interference

\section{Introduction}

Porous silicon $(\mathrm{pSi})$ has become a distinguished material in solar applications. Monocrystalline Si (mono-Si) produced by the Czochralski method is the most commonly substrate for $\mathrm{pSi}$ production. The $\mathrm{pSi}$ is used to produce solar cell with high conversion efficiency (over $21 \%$ ) [1]. Solar cells with a porous structure may be used in transport as part of electric vehicles, electric bicycles and other means of transport using electric drive. These highly efficient solar cells can be used to charge the electric conveying means. Spectral reflectance $R$ of $\mathrm{Si}$ has a significant impact on efficiency of solar cells. $R$ values of untreated mono-Si are over $40 \%$ in range of spectrum relevant for solar cell applications [2]. This high spectral reflectance can be reduced by using anti-reflection layers or by additional surface treatment. The most common methods of surface treatment are for example wet etching (anisotropic, isotropic), electrochemical etching, plasma etching, or metal-assisted chemical etching. The result of application of plasma, electrochemical and metalassisted chemical etching is pSi known as black $\mathrm{Si}$ (b-Si) [1, 3-4]. The most commonly used method of pSi production is electrochemical etching of p-type or n-type $\mathrm{Si}$ substrate in a solution of hydrofluoric acid (HF) and acetonitrile $\left(\mathrm{CH}_{3} \mathrm{CN}\right)$. Porous silicon can also be prepared by electrochemical etching of Si substrate in solution of $\mathrm{HF}$ and dimethylformamide $\left(\mathrm{C}_{3} \mathrm{H}_{7} \mathrm{NO}\right)$ [4-5]. The basic scheme of the principle of electrochemical etching is shown in Figure 1. The principle of electrochemical etching is that an electrical voltage is applied between the anode and the cathode. The cathode is usually made of platinum (Pt) due to its high chemical resistivity. The Pt cathode is separated from the $\mathrm{Si}$ electrode by a few $\mathrm{mm}$ to several $\mathrm{cm}$ of electrolyte solution. There are two regimes of etching of silicon depending on current density: pore formation and electropolishing. Regimes of silicon electrochemical etching in HF solution are shown in Figure 2 [6-7].

The reactions that take place in HF electrolyte are given by equation (pore formation, low current density) [7]:

$\mathrm{Si}+6 \mathrm{H} \rightarrow \mathrm{H}_{2} \mathrm{SiF}_{6}+\mathrm{H}_{2}+2 \mathrm{H}^{+}+2 \mathrm{e}$.
The reactions for electropolishing at high current density are given by equation [7]:

$\mathrm{Si}+6 \mathrm{HF} \rightarrow \mathrm{H}_{2} \mathrm{SiF}_{6}+4 \mathrm{H}^{+}+4 \mathrm{e}:$

In this paper we experimentally study the influence of electrochemical etching conditions to spectral reflectance. Following parameters were changed at electrochemical etching: voltage, etching time and current. The spectral reflectance was significantly modified depending on etching conditions.

\section{Theory of spectral reflectance}

Light impact on the material can be absorbed, reflected, scattered or passed through the medium. The reflection of light can occur from any interface at which the refractive index changes [8]. When light hits a material that has multiple layers with different refractive indices, each layer can reflect light as it is shown in Figure 3. In particular, in the case of the thin layer shown in Figure 3 there is a reflection of the incident wave on its upper and lower surface. The wave reflected from the upper surface of the thin layer is numbered 1 and the wave reflected from the lower surface is numbered 2. The total reflected light is given by the superposition of the reflected waves 1 and 2 . This effect is called interference of light. Interference can be constructive or destructive depending on the phase difference [9].

If the light hits from an interface with a lower refractive index on an interface with a higher refractive index, then the phase shift between reflected and incident light is $180^{\circ}$. Otherwise there will be no phase shift between reflected and incident light [8]. Both cases are shown in Figure 4.

Constructive interference is defined by equation [9]:

$2 n_{2} t \cos \beta=m \lambda, m=0,1,2, \ldots$

\footnotetext{
* Martin Kralik, Michaela Hola, Stanislav Jurecka

Institute of Aurel Stodola, Faculty of Electrical Engineering and Information Technology, University of Zilina, Liptovsky Mikulas, Slovak Republic E-mail:kralik@lm.uniza.sk
} 


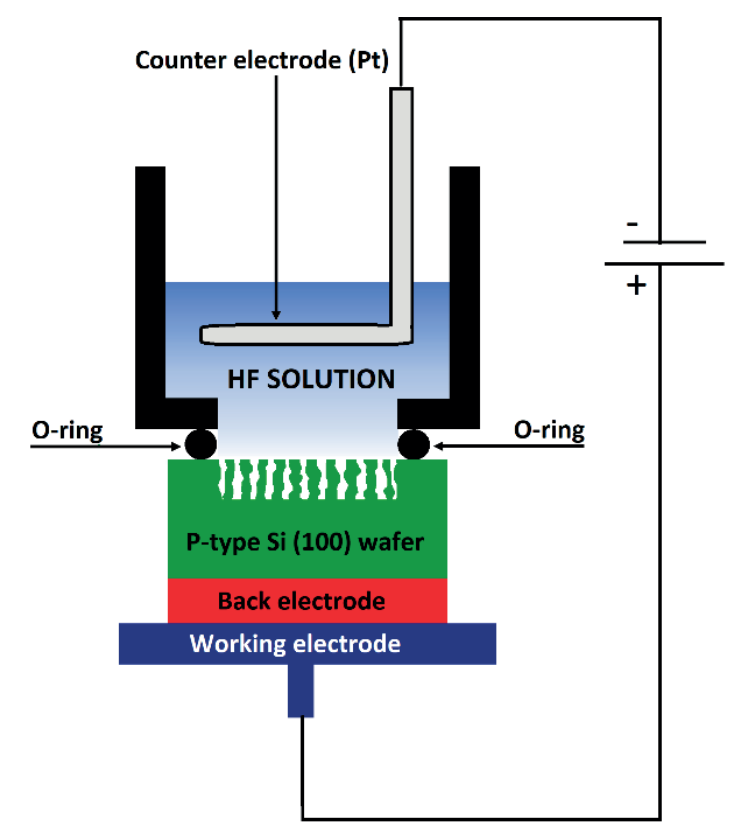

Figure 1 The basic scheme of the principle of electrochemical etching

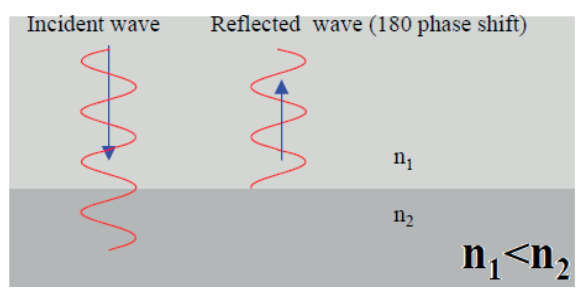

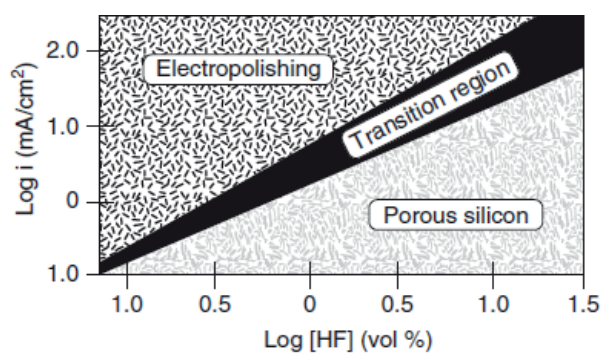

Figure 2 Regimes of silicon electrochemical etching in HF solution: porous silicon formation and electropolishing [7]

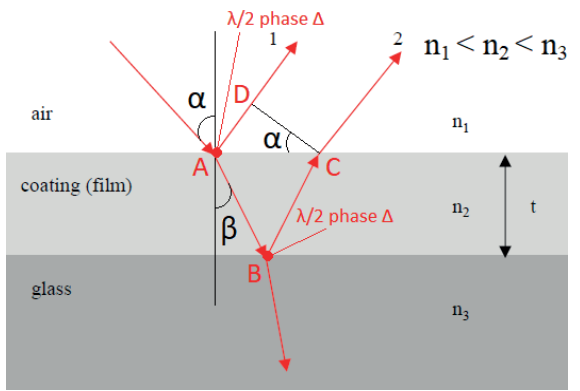

Figure 3 Thin film interference [8]

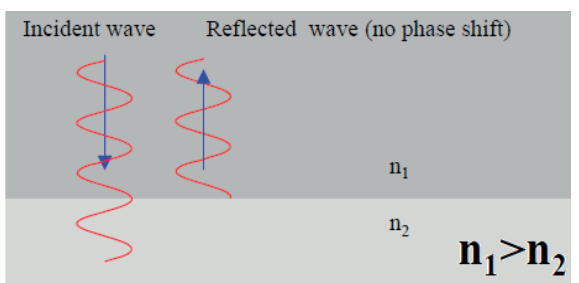

Figure 4 Phase shift between reflected and incident wave is $\lambda / 2$ (left), no phase shift between reflected and incident wave (right) [8]

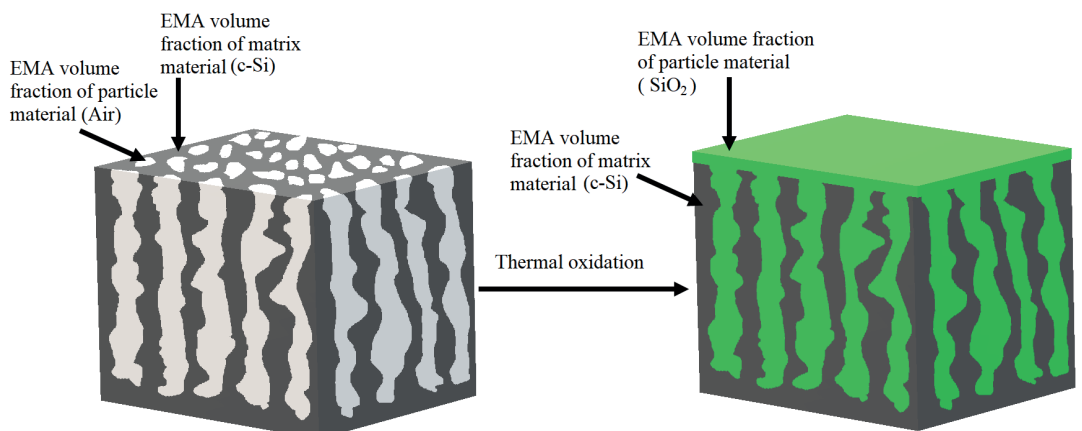

Figure 5 Schematic representation of porous silicon and used volume fractions in Looyenga EMA formula

where $n_{2}$ is refractive index of surface that reflected the wave, $t$ is thickness of layer and $\lambda$ is the wavelength of the incident wave. Destructive interference is defined by equation [9]:

$$
2 n_{2} t \cos \beta=\left(m-\frac{1}{2}\right) \lambda, m=0,1,2, \ldots
$$

The thickness of layer can be determined from the results of measurement of spectral reflectance by using equation [10]:

$$
t=\frac{m}{2 \sqrt{n^{2}-\sin ^{2} \theta}} \frac{1}{\frac{1}{\lambda_{1}}-\frac{1}{\lambda_{2}}},
$$

where $m$ is number of fringes in wavenumber region used, $n$ is refractive index, $\theta$ is angle of incidence, $\lambda_{1}$ a $\lambda_{2}$ are the wavelengths of the used region.
When determining the thickness of the thin layer according to the Equation 5, it is necessary to know the refractive index of the studied material. The refractive index is the function of wavelength. The effective medium approximations (EMA) are the most commonly used for determining the refractive index of pSi. The schematic representation of $\mathrm{pSi}$ structure before and after thermal oxidation process and influence of this process on volume fractions used in Looyenga EMA formula is shown in Figure 5.

\section{Experimental}

The pSi samples published in this paper were prepared within the project APVV-15-0152. The production of pSi samples was performed by the method of electrochemical etching of p-type 
Table 1 Parameters of electrochemical etching

\begin{tabular}{cccccc}
\hline Sample & Voltage $[\mathrm{V}]$ & $\begin{array}{c}\text { Current density } \\
{\left[\mathrm{mA} / \mathrm{cm}^{2}\right]}\end{array}$ & Etching time [min] & $\begin{array}{c}\text { Annealing temperature } \\
{\left[{ }^{\circ} \mathrm{C}\right]}\end{array}$ & Annealing time [min] \\
\hline A & 24.8 & 40 & 1 & 850 & 10 \\
B & 4.2 & 50 & 2.5 & & \\
C & 4.2 & 50 & 5 & & \\
\hline
\end{tabular}

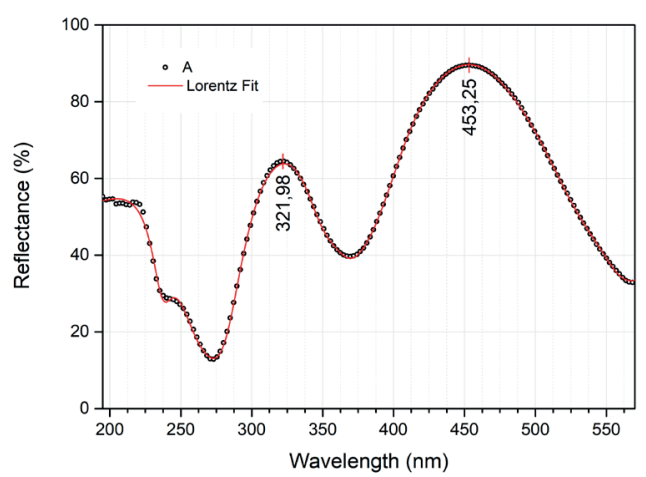

a)

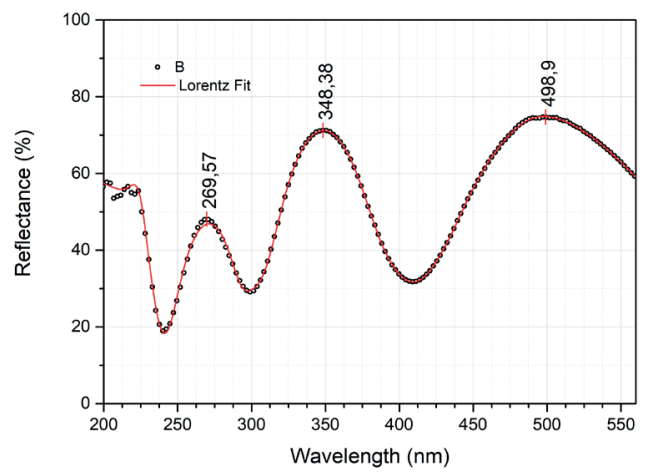

b)

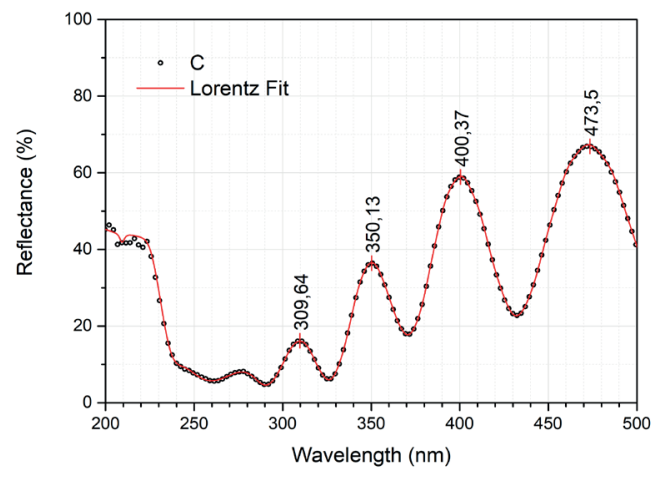

c)

Figure 6 Spectral reflectance of pSi sample a) A, b) B, c) C (dots) and theoretical model - by using a superposition of Lorentzian functions (curve)

Si substrate. After etching samples were annealed in oxygen atmosphere for 10 minutes at $850{ }^{\circ} \mathrm{C}$. The electrochemical etching parameters used for $\mathrm{pSi}$ samples forming are shown in Table 1.

Optical properties of samples were analyzed by using UV/VIS spectrometer AvaSpec-2048 for experimental spectral reflectance determination. The combination of deuterium and halogen lamps was used as a light source in the wavelength range 200-1100 nm. $\mathrm{Al}$ mirror was used as a reference sample.

\section{Results and discussion}

The aim of the experiment was to study the influence of electrochemical etching conditions on spectral reflectance of $\mathrm{pSi}$. Parameters of electrochemical etching are shown in Table 1. The result of electrochemical etching of Si substrate is porous structure. The role of porous structure is to reduce the reflectivity of formed $\mathrm{Si}$ structure. Experimental spectral reflectance of pSi samples A, B and C are shown on Figure 6 (dots). A modification of interference pattern was observed due to changes of microstructure. Increasing number of local spectral reflectance extremes is observed for increasing time and increasing etching current. The thickness of $\mathrm{pSi}$ layer is related to the number of local extremes during the spectral reflectance [10-11]. The thickness of one or more layers in a layer stack can be determined from spectral reflectance by several methods: fast Fourier transformation (FFT) analysis, regression analysis with $\chi^{2}$ test, by using interference pattern and other [10-13].

In this paper we determined the thickness of pSi layers by using theory of thin-film interference by using Equation 5 and Looyenga EMA formula. The results of both methods were compared. The angle of incidence during the reflection measurement was 0 degrees.

The first method for determining layer thickness (theory of thin-film interference) by using Equation 5: Accurate peak positions and number of interference fringes were used for the determination of thicknesses of pSi layers. Peak positions of the interference fringes were determined by using mathematical model of experimental spectral reflectance. This theoretical model was constructed by using a superposition of Lorentzian functions [14-15]: 


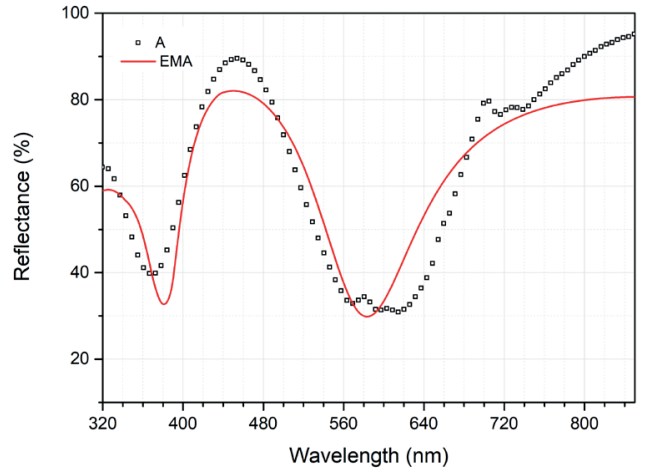

a)

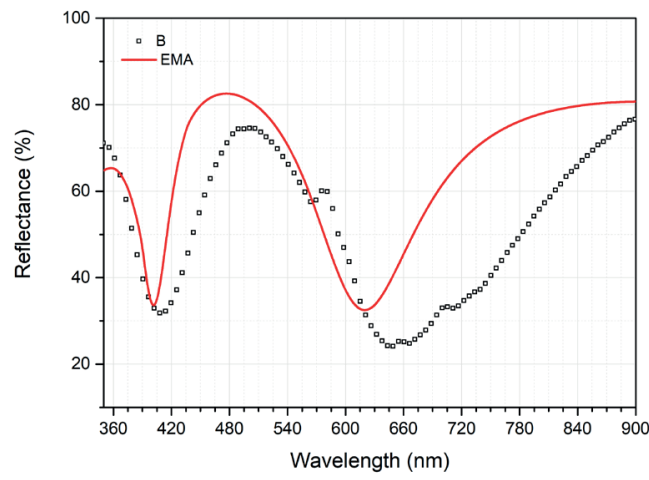

b)

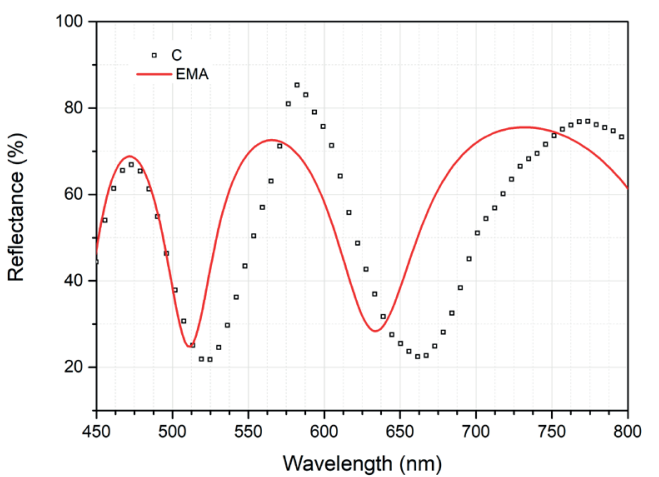

c)

Figure 7 Spectral reflectance of pSi sample a) A, b) B, c) C (dots) and theoretical model - by using Looyenga EMA formula (curve)

Table 2 Thickness of pSi layers

\begin{tabular}{ccc}
\hline Sample & $\begin{array}{c}\text { Layer thickness } \\
\text { (theory of thin-film interference) } \\
(\mathrm{nm})\end{array}$ & $\begin{array}{c}\text { Layer thickness } \\
\text { (Looyenga EMA) } \\
(\mathrm{nm})\end{array}$ \\
\hline A & 206 & 238 \\
B & 217 & 262 \\
C & 497 & 537 \\
\hline
\end{tabular}

$y=y_{0}+\frac{2 A}{\pi} \frac{w}{4\left(x-x_{c}\right)^{2}+w^{2}}$,

where $y_{0}$ is offset, $x_{c}$ is center, $A$ is amplitude, $w$ is width of the Lorentzian peak. Theoretical models of spectral reflectance with marked positions of interference fringes are shown in Figure 6 a), b) and c) (curve). The value of refractive index used in the Equation 5 was 2.7 (50\% volume fraction of $\mathrm{SiO}_{2}(n \sim 1.4585)$ and $50 \%$ volume fraction of $\mathrm{c}-\mathrm{Si}(n \sim 3.9766))$. Calculated thicknesses of pSi layers are shown in Table 2.

The determination of film thickness based on Equation 5 is suitable only for thin film with negligible changes of optical constants in examined wavelength region. Refractive index used in construction of theoretical model of thin film spectral reflectance is obviously determined by suitable dispersion relation or by using selected effective media approximation. Optical properties of porous semiconductor structures are often modeled by using Looyenga EMA approximation due to its low sensitivity to geometrical properties of porous morphology. The Looyenga EMA approximation is defined by equation [16]:

$\varepsilon_{\text {eff }}^{1 / 3}=(1-p) \varepsilon_{m}^{1 / 3}+p \varepsilon_{p}^{1 / 3}$,

where $p$ is the porosity, $\varepsilon_{m}$ and $\varepsilon_{p}$ are the complex dielectric constants of matrix and particle material. We implemented EMA model described by Equation 7 in computation of the spectral reflectance. In our approach crystalline $\mathrm{Si}$ is used as matrix material and $\mathrm{SiO}_{2}$ oxide as particle fraction. Constructed theoretical model was optimized in the SCOUT software. Light scattering from the bottom interface of silicon substrate was not included in the spectral reflectance model due to the thickness of Si substrate $(1 \mathrm{~mm})$. In applied spectral region the light penetration depth in the crystalline Si substrate is very small [17]. Resulting theoretical models of spectral reflectance are shown in Figure 7 a), b) and c) (curve). Calculated thicknesses of pSi layers are shown in Table 2. 


\section{Conclusion}

A modification of interference pattern was observed due to the changes of sample microstructure. We observed increasing thickness of pSi layers influenced by increasing etching time and current density. The increase in thickness due to etching is caused by the formation of porous microstructure on the surface of silicon substrate. The thicknesses of pSi layers in the first case were calculated by using theory of thin film interference. The thicknesses of pSi layers in the second case were calculated in SCOUT software by using Looyenga EMA in construction of theoretical model of spectral reflectance.

As the samples were thermally oxidized, it is likely that the pores were closed on the upper layer, which prevents the diffusion of oxygen to the remaining silicon [18]. For this reason, two volume fractions $\left(\mathrm{SiO}_{2}\right.$ and $\left.\mathrm{c}-\mathrm{Si}\right)$ were used in the Looyenga EMA model.

The results of both methods were compared. Creating an optical model using EMA has been challenging and the results are not ideal, but in this case the results are more reliable than results obtained by using the theory of thin film interference. In the future we will use spectral ellipsometry and Fourier analysis for the determination pSi layer thickness and other important structural properties. We will also work on refinement of optical models.

\section{Acknowledgement}

The work was supported by project H2020-MSCARISE-2016-6260922, grant of Science and Technology Assistance Agency APVV-15-0152, Scientific Grant Agency of the Ministry of Education of Slovak Republic and the Slovak Academy of Sciences project VEGA 1/0676/17, Centre of Excellence of Power Electronics Systems and Materials ITMS 26220120003, No. OPVaV-2008/2.1/01-SORO, ITMS 26220120046, and by project ITMS 26210120021, co-funded from EU sources and European Regional Development Fund.

\section{References}

[1] SAVIN, H., REPO, P., VON GUILLAUME, G., ORTEGA, P., CALLE, E., GARIN M., ALCUBILLA, R. Black silicon solar cells with interdigitated back-contacts achieve $22.1 \%$ efficiency. Nature Nanotechnology [online]. 2015, 10, p. 624-628. ISSN 1748-3387, eISSN 1748-3395. Available from: https://doi.org/10.1038/nnano.2015.89

[2] RAGHUNATHAN, D. Black silicon for higher efficiency in solar cells. Applied Mechanics and Materials [online]. 2015, 787, p. 92-96. ISSN 1662-7482. Available from: https://doi.org/10.4028/www.scientific.net/AMM.787.92

[3] PLAKHOTNYUK, M., DAVIDSEN, R., S., SCHIMDT, M., S., MALUREANU, R., STAMATE, E., HANSEN, O. Lifetime of nano-structured black silicon for photovoltaic applications. 32nd European Photovoltaic Solar Energy Conference and Exhibition : proceedings. 2016. ISBN 978-1-5108-3651-8, p. 764-767.

[4] LOSIC, D., SANTOS, A. Electrochemically engineered nanoporous materials - methods, properties and applications. Springer, 2015. ISBN 978-3-319-20346-1.

[5] LEHMANN, V. Electrochemistry of silicon [online]. Wiley VCH Verlag GmbH, 2002. ISBN 9783527293216 , eISBN 9783527600274. Available from: https://doi.org/10.1002/3527600272

[6] SAILOR, M. J. Porous silicon in practice, preparation, characterization and applications. Wiley VCH Verlag GmbH, 2012. ISBN 978-3-527-31378-5.

[7] FRANSSILA, S. Introduction to microfabrication [online]. 2 ed. John Wiley \& Sons, Ltd, 2010. ISBN 9780470749838 , eISBN 9781119990413. Available from: https://doi.org/10.1002/9781119990413

[8] ROORDA, A. Thin Film Interference. VS203B Lecture Notes, 2011.

[9] SERWAY, R., A., JEWETT, J., W. Physics for scientists and engineers. 6 ed. Belmont, CA, Thomson Brooks/Cole, 2004. ISBN 978-0534408466.

[10] HIND, A., R., CHOMETTE, L. The determination of thin film thickness using reflectance spectroscopy. Application note. Agilent Technologies Inc., SI-A-1205, 2011.

[11] FILMETRICS, Inc. Advanced thin-film measurement systems. Rev. 02.06, 2006.

[12] JURECKA, S., MULLEROVA, J., PINCIK, E. Optical methods for analysis of thin dielectric films. 19th International Conference on Applied Physics of Condensed Matter - APCOM 2013. 2013. ISBN 978-80-227-3956-6, p. 233-236.

[13] GOLDSTEIN, F. Film thickness of 'thick thin films' by spectroscopy. Society of Vacuum Coaters 1998 Meeting. Boston, MA, 1998.

[14] DIRDAL, CH. A., SKAAR, J.: Superpositions of Lorentzians as the class of causal functions. Physical Review A [online]. 2013, 88(3), 033834. ISSN 2469-9926, eISSN 2469-9934. Available from: https://doi.org/10.1103/PhysRevA.88.033834

[15] Origin software: X-Function Register [online]. Avaliable from: https://www.originlab.com/doc/Origin-Help/Lorentz-FitFunc

[16] RAMIREZ-GUTIERREZ, C. F, CASTANO-YEPES, J. D., RODRIGUEZ-GARCIA, M. E. Porosity and roughness determination of porous silicon thin films by genetic algorithms. Optik - International Journal for Light and Electron Optics [online]. 2018, 173, p. 271-278. ISSN 0030-4026. Available from: https://doi.org/10.1016/j.ijleo.2018.08.019

[17] SZE, S. M., KWOK, K. N. Physics of semiconductor devices. Hoboken, John Wiley \& Sons, 2007. ISBN 978-0-471-14323-9. 
[18] FOdOR, B., AGOCS, E., BARDET, B., DEFFORGE, T., CAYREL, F., AlqUIER, D., FRIED, M., GAUTIER, G., PETRIK, P. Porosity and thickness characterization of porous Si and oxidized porous Si layers - an ultraviolet-visible-mid infrared ellipsometry study. Microporous and Mesoporous Materials [online]. 2016, 227, p. 112-120. ISSN 1387-1811. Available from: https://doi.org/10.1016/j.micromeso.2016.02.039 